\title{
COVID-19: IFSO LAC Recommendations for the Resumption of Elective Bariatric Surgery
}

\author{
Estuardo Behrens ${ }^{1,2} \cdot$ Luis Poggi $^{3,4} \cdot$ Sergio Aparicio ${ }^{5} \cdot$ Pedro Martínez Duartez $^{6} \cdot$ Nelson Rodríguez $^{7} \cdot$ Natan Zundel $^{8}$. \\ Almino Ramos Cardoso ${ }^{9}$. Diego Camacho ${ }^{10}$ (D) Juan Antonio López-Corvalá ${ }^{11}$. Marcos Leão Vilas-Bôas ${ }^{5}$. \\ Jorge Laynez ${ }^{12}$
}

Received: 14 May 2020 / Revised: 6 August 2020 / Accepted: 6 August 2020 / Published online: 22 August 2020

(C) Springer Science+Business Media, LLC, part of Springer Nature 2020

\begin{abstract}
Background COVID-19 pandemic varies greatly and has different dynamics in every country, city, and hospital in Latin America. Obesity increases the risk of SARS-CoV-2 infection, and it is one of the independent risk factors for the most severe cases of COVID-19. Currently, the most effective treatment against obesity available is bariatric and metabolic surgery (BMS), which further resolves or improves other independent risk factors like diabetes and hypertension.

Objective Provide recommendations for the resumption of elective BMS during COVID-19 pandemic.

Method This document was created by the IFSO-LAC Executive Board and a task force. Based on data collected from a survey distributed to all IFSO-LAC members that obtained 540 responses, current evidence available, and consensus reached by other scientific societies.

Results The resumption of elective BMS must be a priority maybe similar to oncological surgery, when hospitals reach phase I or II, treating obesity patients in a NON-COVID area, avoiding inadvertent intrahospital contagion from healthcare provider, patients, and relatives. Same BMS indication and types of procedures as before the pandemic. Discard the presence of SARS-
\end{abstract}

Diego Camacho

dicamach@montefiore.org

Estuardo Behrens

ebehrens@comnetsa.com

Luis Poggi

poggiluis@gmail.com

Sergio Aparicio

saparicio@clinicalosolivos.com

Pedro Martínez Duartez

pedromartinez23@hotmail.com

Nelson Rodríguez

nelson.rhmd@gmail.com

Natan Zundel

drnazuma99@yahoo.com

Almino Ramos Cardoso

ramos.almino@gmail.com

Juan Antonio López-Corvalá

drcorvala@grupolap.com

Marcos Leão Vilas-Bôas

marcosleao@me.com
Jorge Laynez

jorgemlaynez@hotmail.com

1 NEW LIFE CENTER, 10 calle 2-45 zona 14. Of. 1202, Guatemala City, Guatemala

2 Bariatric and Metabolic Institute of Guatemala, Guatemala City, Guatemala

3 Department of Surgery Clinica Anglo Americana, Universidad Nacional Mayor de San Marcos, Lima, Peru

4 Peruvian Academy of Surgery, Lima, Peru

5 Clinica los Olivos, Cochabamba Cochabamba, Bolivia

6 Hospital Universitario Austral, Buenos Aires, Argentina

7 Department of Bariatric Surgery, Hospital Puerta de Hierro Andares, Guadalajara, Mexico

8 Buffalo JNMC, Miami, FL, USA

9 Gastro-Obeso-Center Institute of Metabolic Optimization, Sao Pablo, Brazil

10 Department of Surgery, Albert Einstein College of Medicine, Montefiore Medical Center, 111 East 210th Street, Bronx, NY 10467, USA

11 Hospital Ángeles Tijuana Mexico, Tijuana, Mexico

12 Hospital Roosevelt, Guatemala City, Guatemala 
CoV-2 within $72 \mathrm{~h}$ prior to surgery. Continues laparoscopic approach. The entire team use N95 mask. Minimum hospital stays. Implement remote visits for the follow-up.

Conclusion Resumption of elective BMS is crucial because it is not only a weight loss operation but also resolves or improves comorbidities and appears to be an immune restorative procedure of obese patients in the medium term, offering them the same probability of contracting COVID-19 as the regular population.

Keywords Bariatric surgery · COVID-19

\section{Introduction and Background}

On December 2019, Wuhan, China, reported an outbreak of the coronavirus SARS-CoV-2 (COVID-19), an RNA virus that affects the respiratory system and has a high fatality rate especially in adults over the age of 60 and patients suffering obesity and its comorbidities [1-3]. Health systems throughout the world have been stunned by the most serious pandemic so far in the twenty-first century. Italy [4] and Spain [5] have entered a state of disarray and their hospitals have collapsed, despite their infrastructure typical of developed countries.

The virus is known to have a diameter of $0.06-0.14 \mu \mathrm{m}$ and is transmitted by [6-8]:

1 Direct contact: respiratory droplets larger than $54 \mu \mathrm{m}$ propelled into the air up to $2 \mathrm{~m}$ from hands or fomites with secretions, and come into contact with mucous membranes of the mouth, nose, or eyes.

2 Aerial or aerosol transmission: not detected in the SARSCoV-2 outbreak in China, but it could occur during invasive medical procedures in the respiratory tract and upper digestive tract. There is no evidence of fecal transmission, but the virus has been identified in stools and the peritoneal fluid [9]. In the transmission dynamics of asymptomatic cases, it is estimated to occur in 48 to $62 \%$ of the cases, 1 to 3 days before the onset of symptoms, suggesting a high transmission rate even in the asymptomatic period before symptoms appear.

3 Hand contact with the mouth, eyes or nose: The virus can potentially remain viable on surfaces like plastic or steel for several days.

SARS-CoV-2 is highly sensitive to common antiseptics, ultraviolet radiation, and sunlight. For the time being, the use of face masks, face shields, social distancing, and frequent handwashing are the most effective practices to prevent virus spread.

Latin America, as the rest of the world, has been affected by the pandemic. Analyzing the mortality rate per million inhabitants in Latin America (LA), compared to the USA and Europe
(Fig. 1), we find the former has a lower rate than the latter. This is probably because LA is still at a very early phase of the pandemic or because isolation and contention measures were promptly implemented, avoiding new or severe cases to supersede the capacity of the health systems, which would have prevented infected patients from receiving adequate treatment.

An important element to take into consideration is the specific phase of the epidemic in each region or city, as well as hospital units.

Around the globe, more than 2.8 million people die each year due to complications derived from obesity and metabolic syndrome [10-15]. Recent studies have shown that obesity (BMI higher than 30) is one of the independent risk factors that affects the development of the severe forms of the SARSCoV-2 infection, in the same way as cardiovascular disease, type 2 diabetes, hypertension, chronic lung disease, cancer, and chronic kidney disease. [16-23] Therefore, patients with obesity must avoid getting infected with COVID-19 at all costs, adopting the strictest possible preventive measures and resolving their underlying conditions. Currently, the most effective treatment against obesity available is bariatric and metabolic surgery, which further resolves or improves the related comorbidities that are the same risk factors in developing a severe case of SARS-CoV-2. [24-33]

Consequently, we must balance the risk of the disease against the advantages of resuming bariatric and metabolic surgeries as soon as possible. Although this type of interventions can by no means be categorized as emergency surgeries, their postponement causes deterioration of the patient, advances obesity disease and the comorbid conditions that endanger patients' life, and increases the direct and indirect costs of patients' medical treatment [34-39].

Deficiencies in the immune system of morbidly obese individuals is a well-known condition, include elevated levels of eosinophils, monocyte CD14, and monocyte CD14+/CD16+ subsets, with depression of monocyte and neutrophil CD62L. These abnormal levels reverse rapidly with bariatric surgery because it is not only a weight loss operation but also appears to be an immune restorative procedure. [22, 40, 41] 


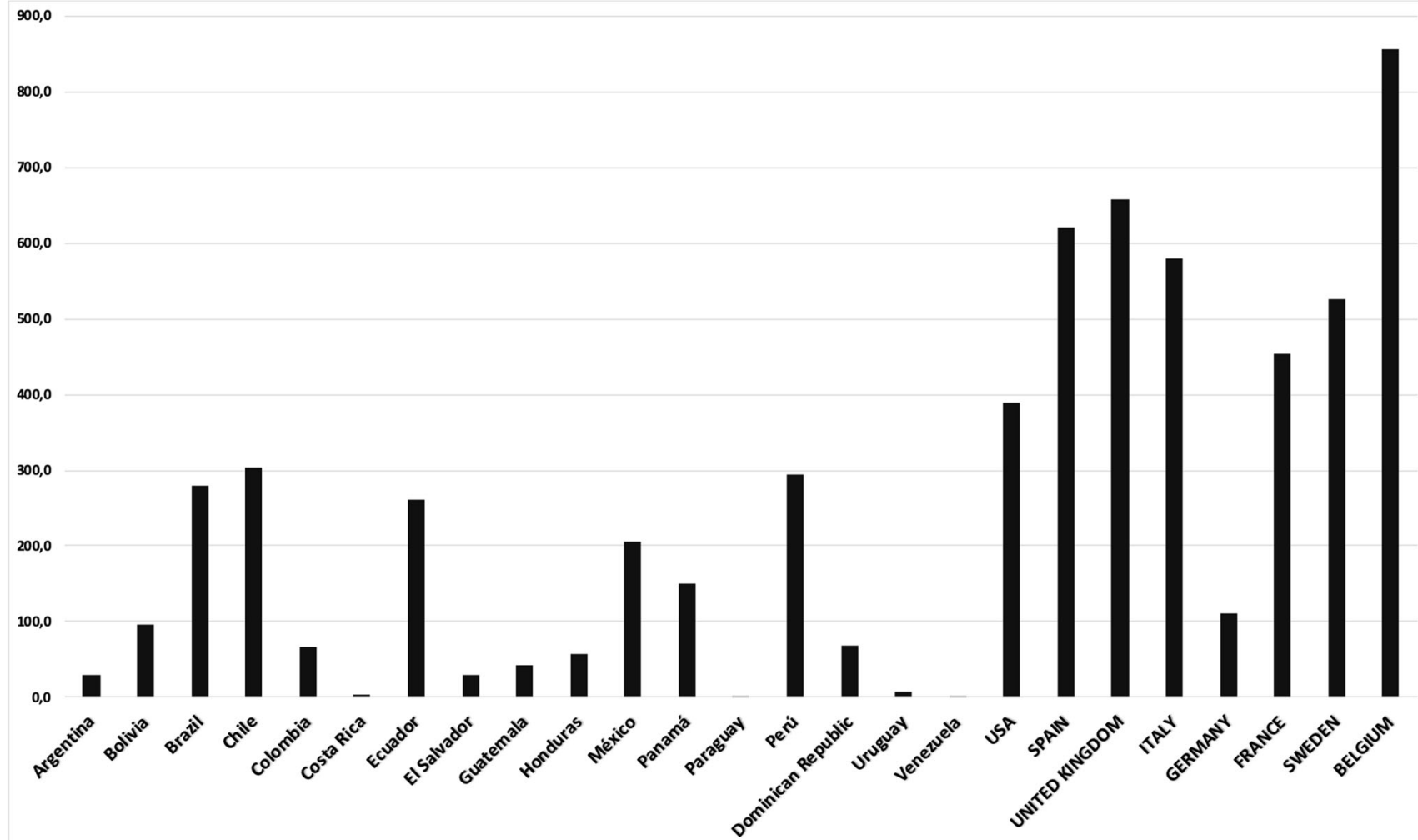

Fig. 1 Mortality rate per million inhabitants (updated July 1, 2020)

COVID-19 pandemic varies greatly and has different dynamics in every country, city, and hospital in Latin America, and special conditions that distinguish it from the rest of the world. Therefore, it demands recommendations, guidelines, and protocols for the resumption of elective bariatric surgery specific for the region. These were jointly formulated by the Executive Board of IFSO LAC and a task force especially commissioned to this end. The resulting document is based on data collected from a survey distributed to all members of IFSO LAC that obtained 540 responses, current evidence readily available, and consensus reached by other scientific societies around the globe [42-53].

\section{Recommendations for the Resumption of Elective Bariatric Surgery}

\section{Priority Level}

The resumption of elective bariatric and metabolic activities must be a priority maybe similar to oncological surgery.

\section{When}

Bariatric surgeries should be resumed when hospitals reach phase I or II as described in the Spanish Association of Surgeons classification (Appendix 1), with preferably less than $15 \%$ of its hospitalization deriving from COVID-19positive patients. In other words, when the capacity of the health system admits pathologies other than COVID-19, but also ensures sufficient resources in the event of a second pandemic wave. Consider the local prevalence of COVID-19.

\section{Where}

It is recommended that elective bariatric surgery be performed in medical facilities with the necessary infrastructure to treat obesity patients in a NON-COVID area.

The hospital must provide at least three areas, ideally with independent circulation amongst them:

- NON-COVID AREA for patients not suspected of having the infection, without symptoms, and with no history of having been in close contact with a person at risk. 
- COVID-POSITIVE AREA for patients with confirmed disease in progress.

- AREA FOR PATIENTS UNDER INVESTIGATION for patients that were admitted into the NON-COVID area and later developed symptoms, and now are under suspicion of infection.

The hospital must also offer exclusive NON-COVID operating rooms as far as possible from operating rooms for positive patients (ideally with negative pressure).

Avoid inadvertent intrahospital contagion (CLOSING THE BACK DOOR):

According to the "Closing the back door" recommendations from the Society of American Gastrointestinal and Endoscopic Surgeons (SAGES), the European Association for Endoscopic Surgery (EAES), and the Spanish Association of Surgery (AEC, for its acronym in Spanish), the following minimum measures must be taken in the care of patients with obesity and other associated conditions for the prevention of unsuspected transmissions from asymptomatic patients in a NONCOVID AREA:

- Healthcare provider

- Negative to the symptoms and epidemiological questionnaire in Table 1.

Table 1 Symptoms and epidemiological questionnaire

\begin{tabular}{l} 
Symptoms questionnaire: \\
Dyspnea \\
Fever \\
Odynophagia \\
Dry cough \\
Diarrhea, nausea, or vomiting \\
Asthenia \\
Anosmia \\
Dysgeusia \\
Myalgia \\
Arthralgia \\
General malaise \\
Headache \\
Epidemiologic questionnaire: \\
Contact with confirmed COVID-19 \\
positive (last 14 days) \\
Travel abroad (last 14 days) \\
Reside or travel to countries with a \\
high viral load (last 24 days) \\
\hline
\end{tabular}

- Temperature control upon entering the hospital (less than $\left.37.5^{\circ} \mathrm{C}\right)$.

- Use of the preventive measures previously established by hospital authorities in accordance with the specific area of work.

- Limit the number of medical visits and, when possible, conduct remote visits by video conference instead.

- Use surgical masks during patient care.

- Assign and divide surgical equipment teams, avoiding contact amongst them during shift changes (preventing contagion from one team to another).

- Observe social distancing in common areas, especially in the cafeterias.

- Wash or sanitize hands according to the Five Moments for Hand Hygiene defined by the World Health Organization (WHO).

- Relatives

- Limit to one companion per patient physically present in the same room, without symptoms and with no history of having been in close contact with a person at risk at least 14 days before the intervention (subject to the questionnaire in Table 1).

- Temperature control upon entering the hospital (less than $37.5^{\circ} \mathrm{C}$ ).

- Request contact information for a second immediate family member.

- Use face masks in public spaces and within the hospital environment permanently.

- Patients

- Medical visits or personal assessments with the multidisciplinary team must be limited and, when possible, coincide with person-to-person visits to conduct physical examinations and complementary studies of the patient. Orientation webinars and online briefings, remote visits by video conference, and virtual groups (i.e., Facebook groups or Zoom meetings) should be implemented for pre- and postoperative consults during the therapeutic process.

- Permanent use of face masks.

- Social distancing 14 days prior to surgery.

- Pre- and postoperative isolation: observe selfisolation and social distancing measures from the date of the preoperative clinical/anesthesia consultation (at least $72 \mathrm{~h}$ previous to surgery and 14 days after).

- Minimize time in the waiting area before and after the procedure.

- Minimal length of stay in the hospital. 
- Daily response to the sanitary questionnaire (clinical and epidemiological) regarding the appearance of new atypical symptoms in the preoperative, hospitalization, and postoperative phases (Table 1).

\section{Patient Selection}

Patient selection in the context of this pandemic will include all of those for whom bariatric or metabolic surgery has been indicated based on current scientific publications applicable to the specific region, and observing the following exclusion criteria: patient decompensation of associated conditions, high-risk patients over the age of 60 , those who need immunosuppressant drugs or suffer chronic lung diseases (chronic obstructive pulmonary disease (COPD) or asthma), and bariatric revisional surgery for insufficient weight loss. The patients should be encouraged to try to lose weight before the surgery.

\section{Assessment and Preoperative Studies}

Preparation protocols for patients with obesity and metabolic syndrome should not be modified from the ones indicated before the pandemic, but should be adjusted to include:

- Clinical survey: conducted by the anesthesiologist or internist 48 to $72 \mathrm{~h}$ previous to the surgery and should inquire about the symptoms that help determine the presence of the disease (Table 1).

- Epidemiological survey: conducted in parallel with the survey mentioned above, to discard close contact with confirmed COVID-19-positive patients in the past 21 days, recent travel abroad to countries with a high viral load in the past 15 days, or hospitalization in other medical institutions (Table 1).

- Laboratory: include microbiology to discard the presence of SARS-CoV-2 (RT-PCR and IgM/IgG serological tests depending on the availability and politics of each country), whose results must be no older than $72 \mathrm{~h}$.

- Imaging: chest radiography performed during the same preanesthetic or clinic consultation and, in cases of uncertainty, thoracic computed tomography (CT), or ultrasound in three quadrants.

Once this last study has been performed, the patient must return home and observe self-isolation up until the day programmed for surgery. On this day, the symptoms and contact questionnaire (Table 1) must be responded again. Any clinical, epidemiological, laboratory, or imaging suspicion of SARS-CoV-2 infection is criteria to postpone surgery until it is discarded, or the patient has met the criteria of healing, at which time the same assessment cycle must be completed.

\section{Informed Consent}

An informed consent must be duly subscribed, specifically indicating that, in the context of the pandemic, the risks associated with the procedure might be higher. Likewise, there is a risk - small but present, nonetheless - to be infected with the SARS-CoV-2 virus during in-patient care.

\section{Operating Room}

- NON-COVID operating rooms must be available, with detailed circulation routes for persons not suspected of having the infection.

- The number of professionals involved in the surgery should be kept to a minimum, and the team should be led by the most experienced surgeon in order to minimize risks, complications, and exposure time in the operating room.

- The number of staff members entering or leaving the operating room must be reduced as much as possible.

\section{Personal Protective Equipment}

Assuming that the patient is by no means suspicious of having a SARS-CoV-2 infection, all personnel entering the sterile field of the operating room should observe the same protection measures as in normal conditions. However, the use of disposable equipment and clothing, face masks (even double piece), and safety glasses is 
Table 2 Procedures that generate aerosols

Ventilation with mask or self-inflating bag

Oropharyngeal aspiration

Collection of respiratory samples

Endotracheal intubation/extubation

Tracheostomy

Bronchoscopy

Upper gastrointestinal endoscopy with open aspiration of the upper respiratory tract

Surgery and procedures with saws and high-speed drills

Dental procedures

Nebulized therapy

Continuous positive airway pressure (CPAP)

Bilevel positive airway pressure (BiPAP)

Cardiopulmonary resuscitation (CPR)

recommended. The use of N95-rated masks is recommended in procedures that generate aerosols (Table 2) and when the medical personnel is over the age of 60 or has any of the high-risk factors for COVID-19. If your institution has the necessary supplies, we suggest that the entire team use N95, which can even be reused.

\section{Surgery}

The laparoscopic approach continues to be the best recommendation, under conditions that prevent pneumoperitoneum and smoke leakage.

Port incisions for laparoscopy must be as small as possible and allow stability but prevent leaks. If the insufflation port must be relocated, it should first be closed before removing the tube and the new port should not be opened until the insufflator tube is connected. The insufflator should be turned on before the new port valve is opened to prevent gas and smoke from back-flowing into the insufflator. A filter should be used for safe gas insufflation, and intra-abdominal pressure must remain low (10$15 \mathrm{mmHg}$ ). An ultrafiltration system or water trap should be used for gas evacuation and, if the insufflator has a smoke evacuation option, it should be used (Appendix Figs. 2 and 3).

Complete evacuation of the pneumoperitoneum must be performed prior to removal of surgical specimens or completing fascial closures.

\section{Recuperation and In-Patient Care}

Recuperation will take place in the NON-COVID area. Postoperative hospital stays should be kept to a minimum and, during hospitalization, the use of postoperative accelerated recovery protocols is recommended. Patients that require intensive monitoring should be admitted to an ICU prepared to this effect for NONCOVID patients (Table 2)

\section{Conclusions}

Although obesity and its comorbidities have long been considered the most severe pandemic in mankind's history, only recently it has been listed as a high-risk condition associated with high mortality rates in the context of the COVID-19 pandemic. It might be possible that timely resumption of elective surgery for the treatment of obesity could enhance the immune systems of these patients in the medium term, offering them the same probability of contracting the disease as the regular population.

In view of the constant changes in the scientific evidence generated by this disease, these recommendations constitute a suggestion and by no means should replace the medical criteria of the attending physician. Moreover, they are susceptible to revisions at any given time and vary according to the realities of each region.

Acknowledgments We thank Gustavo Romero-Velez M.D. for his help and support for this manuscript submission.

\section{Compliance with Ethical Standards}

Conflict of Interest The authors declare that they have no conflict of interest.

Ethical Approval Statement This article does not contain any studies with human participants or animals performed by any of the authors.

Informed Consent Does not apply.

\section{Appendix 1}

Dynamic scale of the different evolutionary phases of the hospitals during the pandemic and how it affects the surgical activity. 


\section{PHASES TO CONSIDER DURING THE EVOLUTION OF THE PANDEMIC}

\begin{tabular}{|c|c|c|c|c|c|}
\hline PHASES & $\begin{array}{l}\text { I (almost } \\
\text { normal) }\end{array}$ & II (mild alert) & III (medium alert) & IV (high alert) & V (emergency) \\
\hline $\begin{array}{l}\text { \% COVID } \\
\text { patients } \\
\text { hospitalized in } \\
\text { regular ward } \\
\text { and ICU }\end{array}$ & $<5 \%$ & $5-25 \%$ & $\mathbf{2 5 - 5 0 \%}$ & $50-75 \%$ & $>75 \%$ \\
\hline $\begin{array}{l}\text { Emergency } \\
\text { care triage }\end{array}$ & No & \multicolumn{4}{|c|}{ Yes (patients with respiratory symptoms vs others) } \\
\hline $\begin{array}{l}\text { Human } \\
\text { resources } \\
\text { and supplies }\end{array}$ & No impact & $\begin{array}{l}\text { No impact but } \\
\text { resources are } \\
\text { reserved, given } \\
\text { the pandemic }\end{array}$ & $\begin{array}{l}\text { Impact on resources } \\
\text { with hospital floors } \\
\text { and ICU beds reserved } \\
\text { for the pandemic }\end{array}$ & $\begin{array}{l}\text { Impact on } \\
\text { resources } \\
\text { and health } \\
\text { professionals }\end{array}$ & $\begin{array}{l}\text { Significant impact with } \\
\text { limited ICU beds and } \\
\text { ventilatory support } \\
\text { resources }\end{array}$ \\
\hline $\begin{array}{l}\text { Surgical } \\
\quad \text { activities }\end{array}$ & Normal & $\begin{array}{l}\text { Oncological urgencies } \\
\text { (if escalation is } \\
\text { ascending, consider } \\
\text { phase III); } \\
\text { preferably } \\
\text { benign (only consider } \\
\text { if in descending } \\
\text { phase) }\end{array}$ & $\begin{array}{l}\text { Oncological urgencies } \\
\text { (no surgeries in at least } \\
\text { three months, could } \\
\text { compromise survival; } \\
\text { no neoadjuvant option } \\
\text { as an alternative; no need } \\
\text { for prolonged stays in } \\
\text { ICU) }\end{array}$ & Urgencies & $\begin{array}{l}\text { Nondeferrable urgencies } \\
\text { and after a } \\
\text { preoperative } \\
\text { triage based on the } \\
\text { ethics } \\
\text { committee }\end{array}$ \\
\hline
\end{tabular}

\section{Appendix 2}

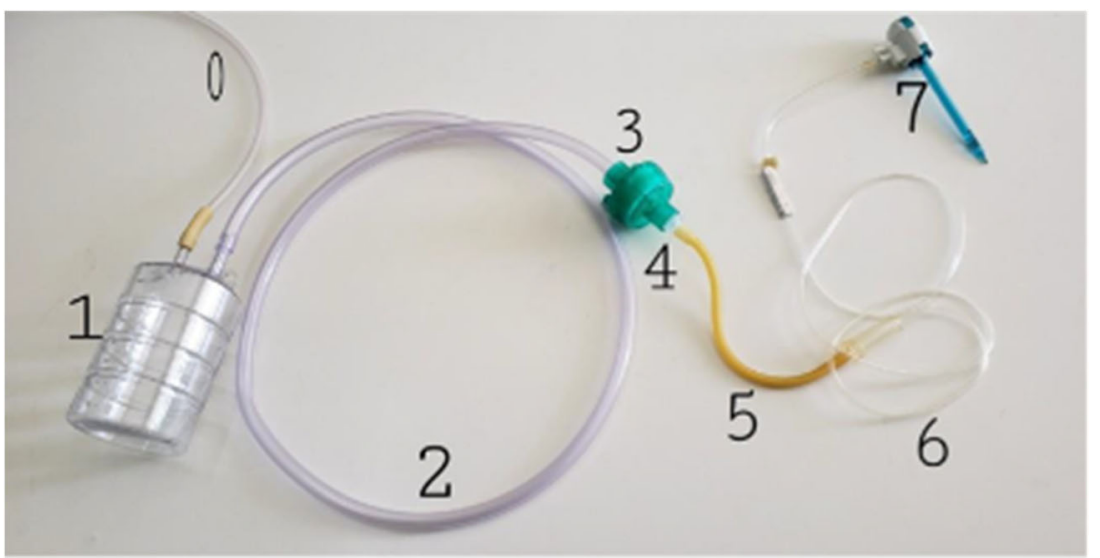

Fig. 2 Smoke evacuation system for the abdominal cavity. (0) Central aspiration outlet connected to short tubbing in water trap. (1) Water trap (any size) with bleach solution (50 cc bleach per 11 of water). (2) K227 tube (or similar) connected to tubbing submerged in water tramp. (3)
High-efficiency particulate air (HEPA)/ultra-low particulate air (ULPA) filter. (4) Endotracheal intubation tube connector. (5) Latex connector between 4 and 6 (could be a latex drainage). (6) V-1. (7) Trocar 


\section{Appendix 3}

\section{CLOSED SYSTEM WATER TRAP FOR THE EVACUATION}

\section{OF SMOKE AND AEROSOLS}
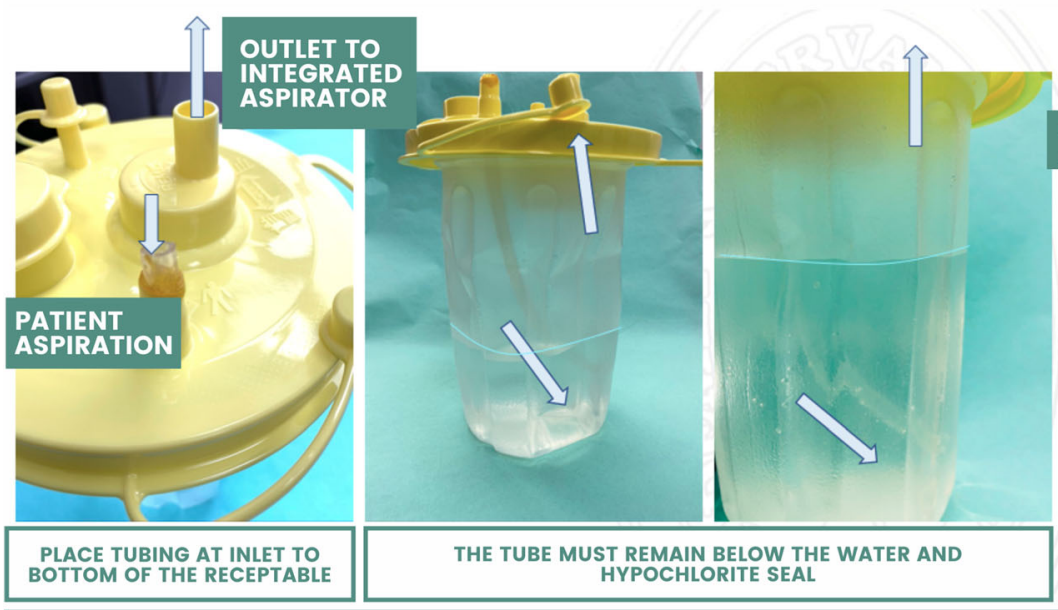

OUTFLOW FILTRATED TOWARDS THE INTEGRATED ASPIRATOR

\section{INSUFFLATOR}

\section{PATIENT}

\section{ASPIRATION TO WATER AND HYPOCHLORITE SEAL}

Fig. 3 Closed system water trap for the evacuation of smoke and aerosols

\section{References}

1. Guan WY, Ni ZY, Hu Y, et al. Clinical characteristics of coronavirus disease 2019 in China. N Engl J Med. 2020;382:1708-20.

2. Huang C, Wang Y, Li X, et al. Clinical features of patients infected with 2019 novel coronavirus in Wuhan, China. Lancet. 2020;395: 497-506.

3. Zhou F, Yu T, Du R, et al. Clinical course and risk factors for mortality of adult inpatients with COVID-19 in Wuhan, China: a retrospective cohort study. Lancet. 2020;395:1054.

4. Ministry of Health, Italy. Coronavirus disease (COVID-19) situation report in Italy. Rome: Ministry of Health, Italy. [Accessed Jun 2020]. Available from: http://www.salute.gov.it/portale/ nuovocoronavirus/dettaglioContenutiNuovoCoronavirus.jsp? lingua $=$ italiano $\& \mathrm{id}=5351 \&$ area $=$ nuovoCoronavirus \&menu=vuoto

5. Ministerio de Sanidad, Consumo y Bienestar Social. [Internet]. España; c2019. [Accessed Jun 2020]. Disponible en: https:// covid19.isciii.es. Royal Decree 463/2020, of March 14, which decrees the state of alarm for the management of health crisis caused by COVID- 19 .

6. Wang D, Hu B, Hu C, et al. Clinical characteristics of 138 hospitalized patients with 2019 novel coronavirus-infected pneumonia in Wuhan, China. JAMA. 2020;

7. Wu Z, McGoogan JM. Characteristics of and important lessons from the coronavirus disease 2019 (COVID-19) outbreak in China: summary of a report of 72,314 cases from the Chinese Center for Disease Control and Prevention. JAMA. 2020;323:1239.
8. Ruan Q, Yang K, Wang W, et al. Clinical predictors of mortality due to COVID-19 based on an analysis of data of 150 patients from Wuhan, China. Intensive Care Med. 2020;

9. Coccolini F, Tartaglia D, Puglisi A, et al. SARS CoV2 is present in peritoneal fluid in COVID 19 patients. Ann Surg. 2020;

10. https://www.who.int/features/factfiles/obesity/en/ [Accessed May 2020]

11. Global BMI Mortality Collaboration, Di Angelantonio E, Bhupathiraju SHN, et al. Body-mass index and all-cause mortality: individual-participant-data meta-analysis of 239 prospective studies in four continents. Lancet. 2016;388(10046):776-86.

12. Warkentin LM, Majumdar SR, Johson JA, et al. Predictors of health-related quality of life in 500 severely obese patients. Obesity (Silver Spring). 2014;22(5):1367-72. https://doi.org/10. 1002/oby.20694.

13. Flegal KM, Kit BK, Orpana H, et al. Association of all-cause mortality with overweight and obesity using standard body mass index categories: a systematic review and meta-analysis. JAMA. 2013;309(1):71-82. https://doi.org/10.1001/jama.2012.113905.

14. Padwal RS, Pajewski NM, Allison DB, et al. Using the Edmonton obesity staging system to predict mortality in a population- representative cohort of people with overweight and obesity. CMAJ. 2011;183(14):E1059-66. https://doi.org/10.1503/cmaj.110387.

15. Whitlock G, Lewington $\mathrm{S}$, et al. Prospective studies collaboration. Body-mass index and cause-specific mortality in 900.000 adults: collaborative analyses of 57 prospective studies. Lancet. 2009;373(9669):1083-96. https://doi.org/10.1016/S01406736(09)60318-4. 
16. Simonnet A, Chetboun M, Poissy J, et al. High prevalence of obesity in severe acute respiratory syndrome coronavirus-2 (SARSCoV-2) requiring invasive mechanical ventilation [published online ahead of print, 2020 Apr 9]. Obesity (Silver Spring). 2020; https:// doi.org/10.1002/oby.22831.

17. Lighter J, Phillips M, Hochman S, et al. Obesity in patients younger than 60 years is a risk factor for Covid-19 hospital admission [published online ahead of print, 2020 Apr 9]. Clin Infect Dis. 2020; ciaa415 https://doi.org/10.1093/cid/ciaa415.

18. Richardson S, Hirsch JS, Narasimhan M, et al. Presenting characteristics, comorbidities, and outcomes among 5700 patients hospitalized with COVID-19 in the New York City area. JAMA. 2020: 2052. https://doi.org/10.1001/jama.2020.6775.

19. Kass DA, Duggal P, Cingolani O. Obesity could shift severe COVID-19 disease to younger ages. Lancet. 2020; https://doi.org/ 10.1016/S0140-6736(20)31024-2.

20. Qingxian C, Chen F, Fang L, et al. Obesity and COVID-19 severity in a designated hospital in Shenzhen, China. 2020; https://doi.org/ 10.2139/ssrn.3556658.

21. Petrilli CM, Jones SA, Yang J, et al. Factors associated with hospitalization and critical illness among 4,103 patients with COVID-19 disease in New York City. medRxiv. https://doi.org/10.1101/2020. 04.08.20057794.

22. Luzi L, Radaelli MG. Influenza and obesity: its odd relationship and the lessons for COVID-19 pandemic. Acta Diabetol. 2020;57(6):759-64. https://doi.org/10.1007/s00592-020-01522-8.

23. Groups at higher risk for severe illness. https://www.cdc.gov/ coronavirus/2019-ncov/need-extra-precautions/groups-at-higherrisk.html. [Accessed May 2020]

24. Hanipah ZN, Schauer PR. Surgical treatment of obesity and diabetes. Gastrointest Endosc Clin N Am. 2017;27(2):191-211. https:// doi.org/10.1016/j.giec.2016.12.005.

25. Kim J, Eisenberg D, Azagury D, et al. ASMBS position statement on long-term survival benefit after metabolic and bariatric surgery. Surg Obes Relat Dis. 2016;12(3):453-9. https://doi.org/10.1016/j. soard.2015.11.021.

26. Rubino F, Nathan DM, Eckel RH, et al. Metabolic surgery in the treatment algorithm for type 2 diabetes: a joint statement by international diabetes organizations. Diabetes Care. 2016;39(6):861-77. https://doi.org/10.2337/dc16-0236.

27. De Luca M, Angrisani L, Himpens J, et al. Indications for surgery for obesity and weight-related diseases: position statements from the International Federation for the Surgery of Obesity and Metabolic Disorders (IFSO). Obes Surg. 2016;26(8):1659-96. https://doi.org/10.1007/s11695-016-2271-4.

28. Ackermann M, Alva O, Alvarez MG, et al. Consenso de cirugía metabólica en Argentina (Consensus of Metabolic Surgery in Argentina). Rev Soc Arg de Diabetes. 2015;49(3):95-110.

29. Ricci C, Gaeta M, Rausa E, et al. Long-term effects of bariatric surgery on type II diabetes, hypertension and hyperlipidemia: a meta-analysis and meta-regression study with 5-year follow-up. Obes Surg. 2015;25(3):397-405.

30. Chang SH, Stoll CR, Song J, et al. The effectiveness and risks of bariatric surgery: an updated systematic review and meta-analysis, 2003-2012. JAMA Surg. 2014;149(3):275-87.

31. Puzziferri N, Roshek TB, Mayo HG, et al. Long-term follow-up after bariatric surgery: a systematic review. JAMA. 2014;312(9): 934-42.

32. Busetto L, Dixon J, De Luca M, et al. Bariatric surgery in class I obesity: a position statement from the International Federation for the Surgery of Obesity and Metabolic Disorders (IFSO). Obes Surg. 2014;24(4):487-519. https://doi.org/10.1007/s11695-014-1214-1.

33. Neff KJ, le Roux CW. Bariatric surgery: the indications in metabolic disease. Dig Surg. 2014;31(1):6-12. https://doi.org/10.1159/ 000351440 .
34. Casimiro Pérez JA, Fernández Quesada C, Del Val Groba Marco $\mathrm{M}$, et al. Obesity surgery score (OSS) for prioritization in the bariatric surgery waiting list: a need of public health systems and a literature review. Obes Surg. 2018;28(4):1175-84. https://doi.org/ 10.1007/s11695-017-3107-6.

35. Arteaga-González IJ, Martín-Malagón AI, Ruiz de Adana JC, et al. Bariatric surgery waiting lists in Spain. Obes Surg. 2018;28(12): 3992-6. https://doi.org/10.1007/s11695-018-3453-z.

36. Cohen RV, Luque A, Junqueira $\mathrm{S}$, et al. What is the impact on the healthcare system if access to bariatric surgery is delayed? Surg Obes Relat Dis. 2017;13(9):1619-27. https://doi.org/10.1016/j. soard.2017.03.025.

37. Flanagan E, Ghaderi I, Overby DW, et al. Reduced survival in bariatric surgery candidates delayed or denied by lack of insurance approval. Am Surg. 2016;82(2):166-70.

38. Lakoff JM, Ellsmere J, Ransom T. Cause of death in patients awaiting bariatric surgery. Can J Surg. 2015;58(1):15-8. https:// doi.org/10.1503/cjs.002914.

39. Al Harakeh AB, Burkhamer KJ, Kallies KJ, et al. Natural history and metabolic consequences of morbid obesity for patients denied coverage for bariatric surgery. Surg Obes Relat Dis. 2010;6(6):5916.

40. Cottam DR, Schaefer PA, Shaftan GW, et al. Effect of surgicallyinduced weight loss on leukocyte indicators of chronic inflammation in morbid obesity. Obes Surg. 2002;12(3):335-42. https://doi. org/10.1381/096089202321088101.

41. Moulin CM, Rizzo LV, Halpern A. Effect of surgery-induced weight loss on immune function. Expert Rev Gastroenterol Hepatol. 2008;2(5):617-9. https://doi.org/10.1586/17474124.2.5. 617.

42. Prachand VN, Milner R, Angelos P, et al. Medically necessary, time-sensitive procedures: scoring system to ethically and efficiently manage resource scarcity and provider risk during the COVID19 pandemic [published online ahead of print, 2020 Apr 9]. J Am Coll Surg. 2020;S1072-7515(20):30317-3. https://doi.org/10. 1016/j.jamcollsurg.2020.04.011.

43. Lei S, Jiang F, Su W, et al. Clinical characteristics and outcomes of patients undergoing surgeries during the incubation period of COVID-19 infection [published online ahead of print, 2020 Apr 5]. EClinicalMedicine. 2020:100331. https://doi.org/10.1016/ j.eclinm.2020.100331.

44. Tuech JJ, Gangloff A, Di Fiore F, et al. Strategy for the practice of digestive and oncological surgery during the Covid-19 epidemic [published online ahead of print, 2020 Mar 31]. J Visc Surg. 2020;S1878-7886(20):30070-9. https://doi.org/10.1016/j. jviscsurg.2020.03.008.

45. Forrester JD, Nassar AK, Maggio PM, et al. Precautions for operating room team members during the COVID-19 pandemic [published online ahead of print, 2020 Apr 2]. J Am Coll Surg. 2020;S1072-7515(20):30303. https://doi.org/10.1016/j. jamcollsurg.2020.03.030.

46. Joint Statement Roadmap for Resuming Elective Surgery after COVID-19 Pandemic 41720update por American College of Surgeons, American Society of Anesthesiologists, Association of periOperative Registered Nurses, American Hospital Association. https://www.asahq.org/about-asa/newsroom/news-releases/2020/ 04/joint-statement-on-elective-surgery-after-covid-19-pandemic [Accessed May 2020]

47. Recomendaciones de la Asociación Española de Cirugía (Recommendations of the Spanish Association of Surgery). https://www.aecirujanos.es/Documentos-de-posicionamiento-yrecomendaciones-de-la-AEC-en-relacion-con-la-cirugia-yCOVID19 es 1 152.html [Accessed May 2020]

48. Recomendaciones del Colegio Americano de Cirugía (Recommendations of the American College of Surgeons ACS). https://www.facs.org/covid-19 [Accessed May 2020] 
49. Recomendaciones de la Sociedad Americana de cirujanos gastrointestinales y endoscopistas (Recommendations of the Society of American Gastrointestinal and Endoscopic Surgeons). https://www.sages.org/category/covid-19/ [Accessed May 2020]

50. Surgical services protocol from Hospital Universitario Virgen del Rocio de Sevilla (Spain) and surgical services from Hospital de Pavia (Italy). https://www.hospitaluvrocio.es/entrada-blog/ protocolos-c-general-covid-19/ [Accessed May 2020]

51. Surgical care protocol during the COVID-19 pandemic. QUIRON SALUD (Spain), updated April 16, 2020 [Accessed May 2020]

52. Recomendaciones de la Sociedad Americana de Cirugía Bariatrica y Metabólica https://asmbs.org/resources/covid-19-resource-center [Accessed May 2020]
53. Rubino F, Cohen R, Mingrone, et al. Bariatric and metabolic surgery during and after the COVID-19 pandemic: DSS recommendations for management of surgical candidates and postoperative patients and prioritisation of access to surgery. Lancet Diabetes Endocrinol. 2020; https://doi.org/10.1016/ S2213-8587(20)30157-1.

Publisher's Note Springer Nature remains neutral with regard to jurisdictional claims in published maps and institutional affiliations. 